\title{
Expression of proliferating cell nuclear antigen in hyperplastic polyps, adenomas and inflammatory cloacogenic polyps of the large intestine
}

\author{
N J Carr, J M Monihan, U C Nzeako, L A Murakata, L H Sobin
}

\begin{abstract}
Aims-To compare proliferating cell nuclear antigen (PCNA) immunoexpression in hyperplastic polyps, adenomas, and inflammatory cloacogenic polyps of the human colon and rectum using paraffin wax embedded tissue.

Methods-The monoclonal antibody PC10 was used to demonstrate PCNA immunoreactivity in 88 polypoid lesions from 68 patients. Cases in which immunoexpression was completely absent were excluded, leaving 32 hyperplastic polyps, 31 adenomas, and seven inflammatory cloacogenic polyps for analysis. Labelling indices for the upper and lower third of each lesion and for adjacent normal mucosa were calculated.
\end{abstract}

Results-The upper third labelling indices for adenomas were substantially higher than those for hyperplastic polyps or normal mucosa, whereas those for the upper thirds of hyperplastic polyps and normal mucosa did not differ greatly. The differences between the lower third samples were not significant. In 16 (50\%) hyperplastic polyps positive cells persisted onto the luminal surface. Some adenomas showed the most intense staining and the highest labelling indices in the upper third, with strong staining of surface cells; this pattern was not seen in the other lesions. The inflammatory cloacogenic polyps did not show a consistent pattern of immunoexpression.

Conclusions-Differences in cell kinetics between adenomas, hyperplastic polyps, and normal mucosa may be shown in formalin fixed, paraffin wax embedded tissue using PC10 as a marker of proliferative activity. PCNA expression also persists into the upper portions of hyperplastic polyps. Assuming that hyperplastic polyps are hypermature lesions with a slower rate of cell migration, this finding suggests that there may be an alteration in PCNA protein metabolism. (F Clin Pathol 1995;48:46-52)

Keywords: Large intestinal polyps, proliferating cell nuclear antigen, inflammatory cloacogenic polyp.

Previous studies comparing the cell kinetics of hyperplastic polyps and adenomas of the large intestine used techniques requiring fresh tissue. ${ }^{1-3}$ The aim of this study was to compare patterns of proliferative activity in these lesions in routinely processed tissue using proliferating cell nuclear antigen (PCNA) immunoexpression. We also wished to determine whether PCNA immunoexpression in colorectal polypoid lesions might be of use for differential diagnosis in cases not readily classified on routine histological stains. For example, inflammatory cloacogenic polyps, reactive lesions believed to form part of the spectrum of the mucosal prolapse syndrome, ${ }^{4-6}$ may mimic adenomatous lesions histologically. ${ }^{67}$ Therefore, in addition to cases of hyperplastic polyp and adenoma, we examined a group of inflammatory cloacogenic polyps as an example of a type of lesion which is proliferative and reactive in nature rather than neoplastic, but which may be difficult to distinguish from adenoma morphologically.

PCNA is found in both prokaryote and eukaryote species and co-localises with tritiated thymidine in the nucleus of replicating cells. ${ }^{8}$ The PCNA gene product is a 36 kilodalton nuclear non-histone protein which appears to be highly conserved throughout evolution ${ }^{9}{ }^{10}$ and is believed to be a co-factor for DNA polymerase..$^{11}$ PCNA expression correlates well with other measures of proliferative activity ${ }^{11-19}$ and monoclonal antibodies that recognise PCNA are suitable for assessing cell proliferation in archival tissue. ${ }^{8-101720}$ PCNA is also involved in the repair of damaged DNA (that is, nucleotide excision and repair) and is associated with chromatin at all stages of the cell cycle after ultraviolet irradiation both in vivo and in vitro. ${ }^{10}$ To reveal PCNA, we used a mouse monoclonal antibody, PC10, which reacts with this antigen in normal and neoplastic tissues following formalin fixation and embedding in paraffin wax. ${ }^{91020}$

\section{Methods}

Cases diagnosed as adenoma, hyperplastic polyp, or inflammatory cloacogenic polyp between 1983 and 1993 were retrieved from the files of the Armed Forces Institute of Pathology (AFIP), Washington DC, USA. Demographic details were obtained from the case notes in accordance with the AFIP Human Use Committee and the statutes of the Privacy Act. We selected 88 lesions \\ Aylesbury, Halton, \\ Buckinghamshire \\ HP22 5PG \\ N J Carr
}


from 68 patients: 40 hyperplastic polyps, 41 adenomas, and seven inflammatory cloacogenic polyps on the basis that adequate material was available for study. The presence of atypia in the epithelium of the inflammatory cloacogenic polyps had led the contributing pathologists to raise the possibility of a neoplastic lesion. Formalin fixed, paraffin wax embedded tissue was available in each case. Slides were stained with haematoxylin and eosin to confirm the diagnoses and each lesion was classified according to the criteria of the World Health Organisation. ${ }^{7}$

Immunohistochemical studies were performed as follows: sections were deparaffinised at $60^{\circ} \mathrm{C}$ for 30 minutes, rinsed four times with xylene, four times with ethanol, and once with a solution of $50 \mathrm{ml} \mathrm{30 \%}$ hydrogen peroxide in $450 \mathrm{ml}$ methanol. The tissue was incubated overnight in a $10 \%$ solution of horse serum in phosphate buffered saline (PBS). The primary antibody, PC10 (Dako, Glostrup, Denmark), was diluted 1 in 40 and applied to the sections for 30 minutes. The slides were rinsed with PBS, incubated twice with $10 \%$ horse serum in PBS for 10 minutes each, and rinsed with PBS again. The secondary antibody, a horse anti-mouse serum (Vector Labs, Burlingham, California, USA) diluted 1 in 800 , was then applied for $30 \mathrm{~min}$ utes, rinsed with PBS, followed by application of an avidin biotin complex supplied in kit form (Vectastain kit, Vector Labs). The slides were incubated in $0.016 \%$ diaminobenzidine in PBS with $400 \mathrm{ml} \mathrm{30 \%}$ hydrogen peroxide in $500 \mathrm{ml}$ PBS for 15 minutes and were then rinsed with deionised water. The slides were counterstained with Gill's haematoxylin and mounted. Positive and negative controls were used for each set of slides.

The test slides were then examined to determine the pattern of immunoreactivity in each lesion. The following variables were specifically assessed: (i) the labelling index of the lower third of the lesion; (ii) the labelling index of the upper third of the lesion; and (iii) the presence or absence of positive cells on the surface of the lesion. The labelling index was calculated by giving the proportion of cells exhibiting positive nuclear immunoreactivity in each zone as a percentage. This calculation may be expressed as a mathematical formula:

$$
\mathrm{I}=100 \mathrm{p} / \mathrm{t}
$$

where $\mathrm{I}=$ labelling index; $\mathrm{p}=$ number of positive cells counted; and $t=$ total number of cells counted (both positive and negative). Slides showing normal mucosa away from the lesion were further assessed to determine the labelling indices in the lower and upper thirds of histologically normal crypts. To achieve this, we performed counts in crypts which appeared normal and were located at least 2 $\mathrm{mm}$ away from the nearest abnormal epithelium. The number of test slides per lesion varied from one to three and the total number of cells counted per slide varied from 300 to 1000 for the hyperplastic polyps and adeno- mas, 500 to 2000 for the inflammatory cloacogenic polyps, and a further 300 to 800 cells in the slides with normal mucosa.

To determine the appropriateness of using parametric tests for our data, each labelling index sample was tested for goodness-of-fit to the Gaussian distribution, using d'Agostino's test of Normality. ${ }^{21}$ Results of this test for the upper and lower thirds of normal mucosa, hyperplastic polyps, and adenomas did not show a significant departure from the Gaussian distribution. An assumption of Normality was therefore considered valid, and the Student's $t$ test for independent samples was used to assess the significance of differences between the samples under study with respect to labelling indices.

To determine whether the proportion of hyperplastic polyps showing positive immunostaining on the luminal surface was significantly different from the same proportion in normal mucosa, the $\chi^{2}$ test with continuity correction was used. Because of the relatively small size of our sample, a Contingency Table Randomisation Test ${ }^{22}$ was used to assess whether there was a significant correlation between the pattern of immunoreactivity observed in our sample of adenomas and the type of adenoma (that is, tubular, tubulovillous, or villous). All $\mathrm{p}$ values stated are two-tailed probabilities; a $p$ value of $<0.05$ was considered significant.

The reliability of the labelling indices was tested by estimating the interobserver variation on a random sample of 20 cases each examined independently by three pathologists. The estimator of reliability, $r$, between these observers was determined using repeated measures analysis of variance as described by Winer. ${ }^{23}$ The statistic $r$ is a number between zero and one, with zero indicating no agreement between observers and one indicating perfect agreement. ${ }^{24}$

\section{Results}

A few cases showed a complete absence of PCNA immunoexpression. These lesions, eight (20\%) hyperplastic polyps and $10(24 \%)$ adenomas, were excluded from the analysis. The remaining lesions were as follows: 32 hyperplastic polyps from 24 patients (mean age 56 years, range 38 to 78 years; male:female ratio 15:9), 31 adenomas from 29 patients (mean age 63 years, range 30 to 78 years; male:female ratio $20: 9$ ) and seven inflammatory cloacogenic polyps from seven patients (mean age 55 years, range 38 to 71 years; male:female ratio $4: 3$ ). Normal mucosa was assessed in a total of 23 cases: eight patients with hyperplastic polyps, 14 patients with adenomas, and one patient with an inflammatory cloacogenic polyp (mean age 67 years, range 46 to 77 years; male:female ratio 12:8). None of these patients was a known case of a polyposis syndrome.

The $r$ value calculated using analysis of variance was 0.83 , indicating good agreement between observers in this study and exceeded the 0.75 cut off value suggested by Brambilla 
Figure 1

Immunohistochemical reaction for PCNA in normal mucosa. The positive nuclear signal for $P C N A$ is strongest in the lower third of the crypts. This specimen showed an adenoma elsewhere.

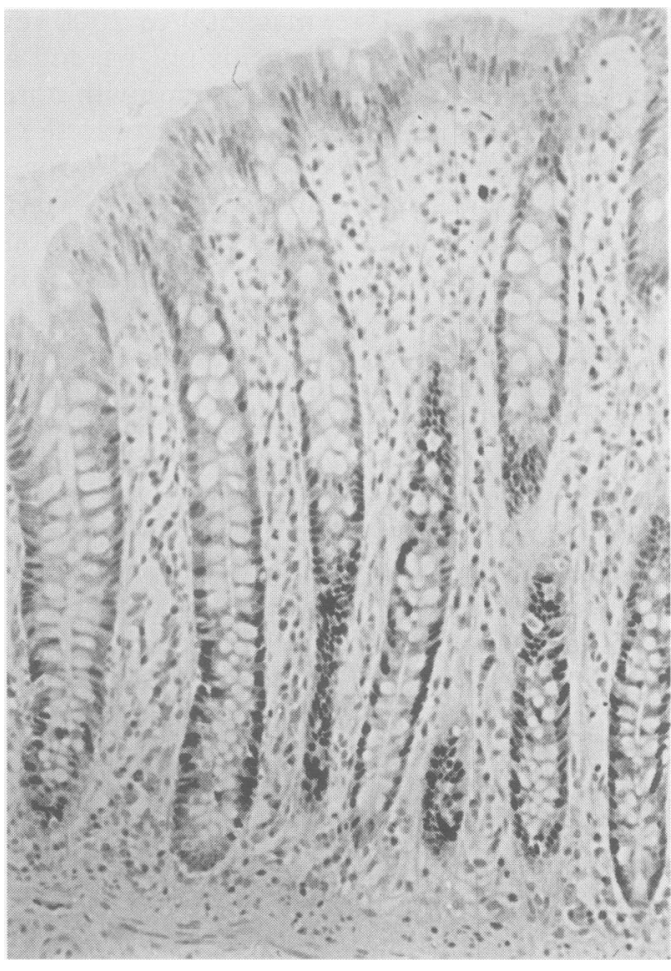

Table 1 Labelling indices for normal mucosa, hyperplastic polyps and adenomas

\begin{tabular}{lllll}
\hline Type of lesion & Position & Mean LI (\%) & Median LI (\%) & Range \\
\hline Normal & Upper third & 22.3 & 15.5 & 0 to 59 \\
mucosa (n=23) & Lower third & 53.8 & 49.0 & 5 to 91 \\
Hyperplastic & Upper third & 27.5 & 25.5 & 1 to 59 \\
polyps $(\mathrm{n}=32)$ & Lower third & 52.9 & 51.0 & 9 to 93 \\
Adenomas & Upper third & $57 \cdot 8^{\star \star}$ & 53.0 & 19 to 97 \\
(n=31) & Lower third & 59.9 & 63.0 & 15 to 96 \\
\hline
\end{tabular}

$\mathrm{LI}=$ labelling index; $\mathrm{n}=$ number of lesions analysed. ${ }^{\star \star} \mathrm{p}<0.001$ when compared either with mean LI for upper third of normal mucosa or mean LI for upper third of hyperplastic polyps.

et $a l^{24}$ as the minimum useful reliability requirement.

Normal mucosa away from the lesions showed the most intense staining in the lower third (fig 1). The number of positive cells and the intensity of the staining decreased pro-

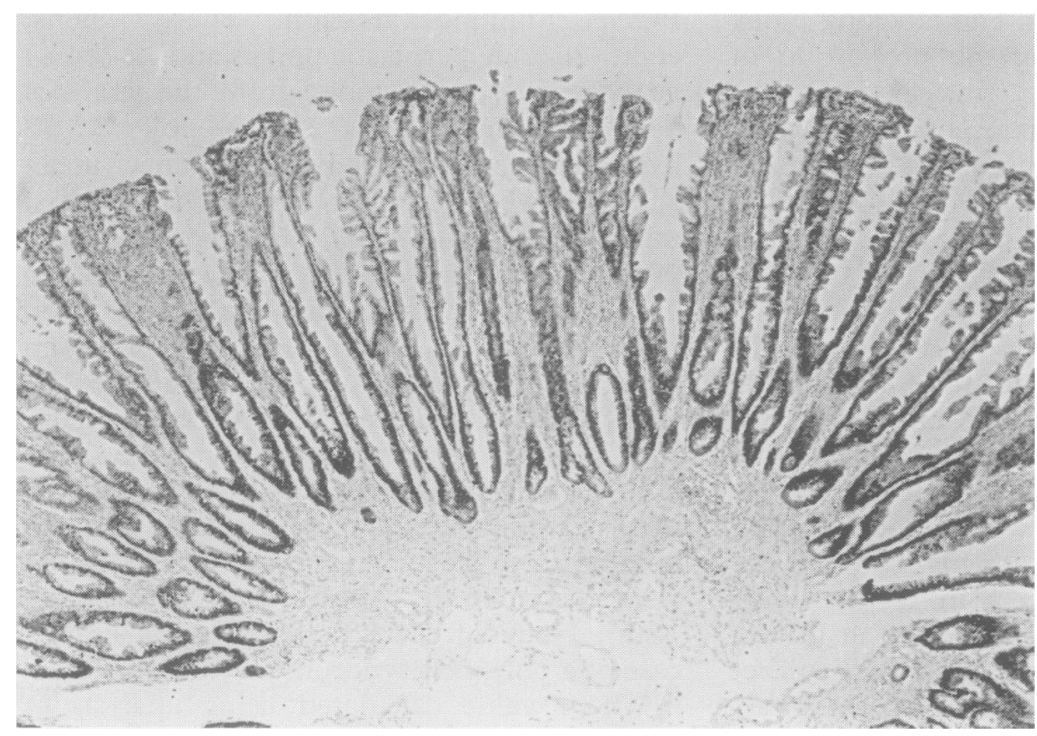

Figure 2 Immunohistochemical reaction for PCNA in a hyperplastic polyp. The lower third shows the strongest PCNA immunoreactivity, but positive cells are also present in the upper portions. gressively towardis the luminal surface, but in eight $(35 \%)$ cases a positive nuclear signal persisted in cells on the luminal surface (six of these eight cases had adenomas and the remaining two had hyperplastic polyps). The labelling indices reflected these observations and are presented in table 1.

Hyperplastic polyps and adenomas showed a greater variation in immunoexpression between different areas than normal mucosa. This variability within sections was taken into account when determining the optimum number of cells to count. We also noted that cautery artefact abolished immunoexpression of PCNA and areas exhibiting thermal changes were excluded from analysis.

Hyperplastic polyps displayed the most intense positive staining in their lower portions (fig 2). The number of positive cells and the intensity of the positive nuclear signal diminished on nearing the luminal surface. This observation, reflected in the labelling indices, was analogous to the distribution of staining in normal mucosa. In 16 of the hyperplastic polyps immunoreactive cells were present on the luminal surface.

The adenoma group included lesions categorised as tubular (16 lesions), tubulovillous (10 lesions), and villous (five lesions). We classified eight as having mild dysplasia, nine as having moderate dysplasia, and 14 as having severe dysplasia. We observed two main patterns of immunoreactivity. In the first the most intense staining and the highest labelling indices were seen in the lower portions of the lesions, with a progressive decrease in positive signal on nearing the surface (fig $3 \mathrm{~A}$ ). This pattern was qualitatively similar to that observed in the normal mucosa and the hyperplastic polyps, and was seen mainly in lesions with mild or moderate dysplasia. The second pattern was characterised by the most intense staining and the highest labelling indices being found in the upper third. In these cases there was consistent strong staining of a high proportion of cells on the surface of the lesions (fig 3B). Moreover, all lesions showing this pattern were classified as moderately or severely dysplastic. The first pattern was seen alone in 17 lesions, the second in six lesions, and both patterns in different areas in eight lesions. Comparison with the haematoxylin and eosin stained slides showed that the areas with the highest labelling indices corresponded to the areas showing the highest grade of dysplasia in a particular lesion. Of the adenomas, 30 (97\%) showed a positive nuclear signal in cells on the luminal surface.

Inflammatory cloacogenic polyps did not show a consistent pattern of immunoexpression. Two cases exhibited strong immunoreactivity throughout, with no appreciable difference between upper and lower portions (fig 4). Both of these cases had positive cells on the surface. Three lesions showed a pattern of immunoreactivity resembling normal mucosa-that is, the highest labelling index was in the lower third. One of the cases had positive cells on the surface. The remaining 

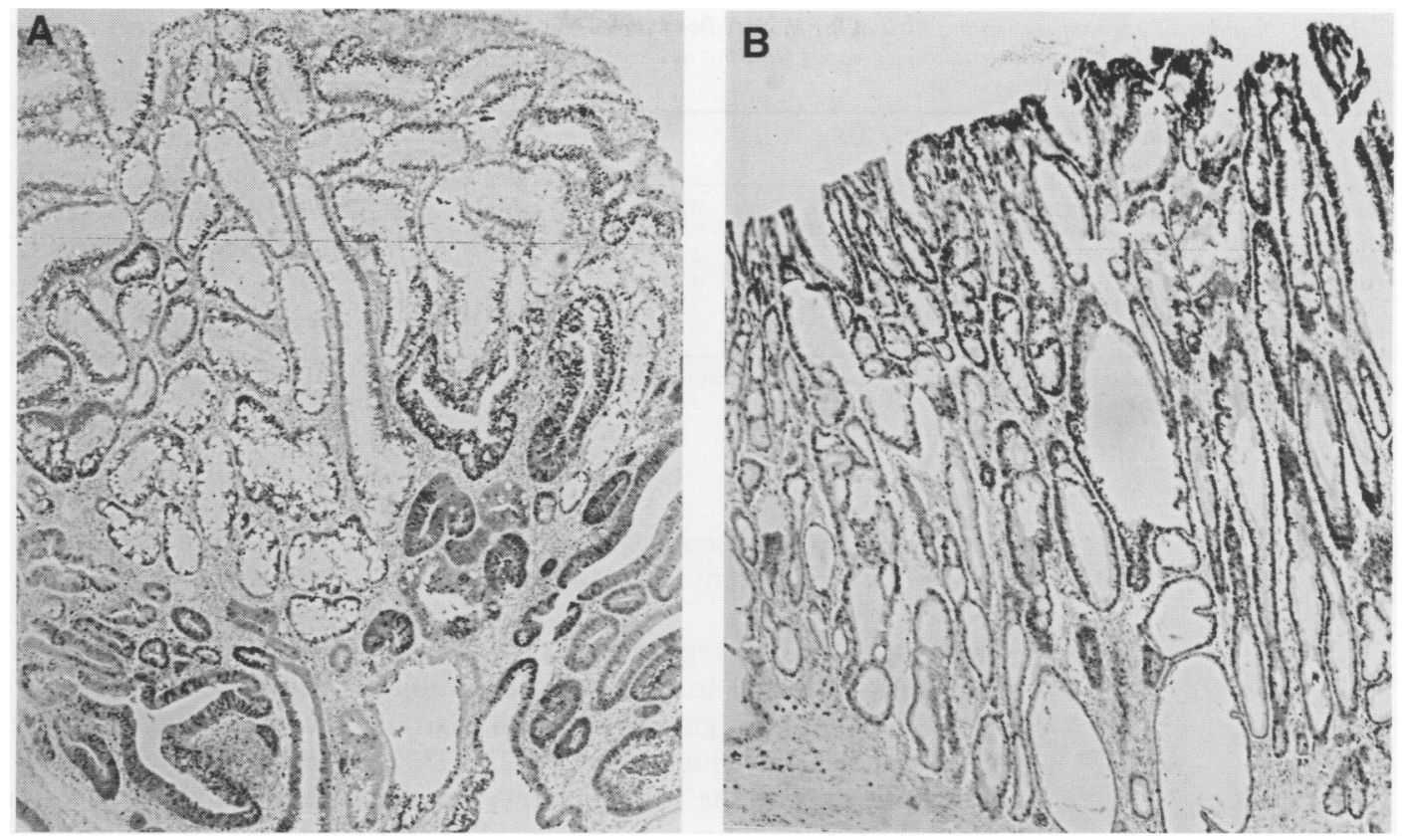

Figure 3 A: Immunohistochemical reaction for PCNA in a tubular adenoma. In this lesion the PCNA labelling index in the lower third is greater than that in the upper third. B: Tubular adenoma showing strong PCNA immunoreactivity in the upper portions and on the surface. The labelling index in the upper third is greater than in the lower third.
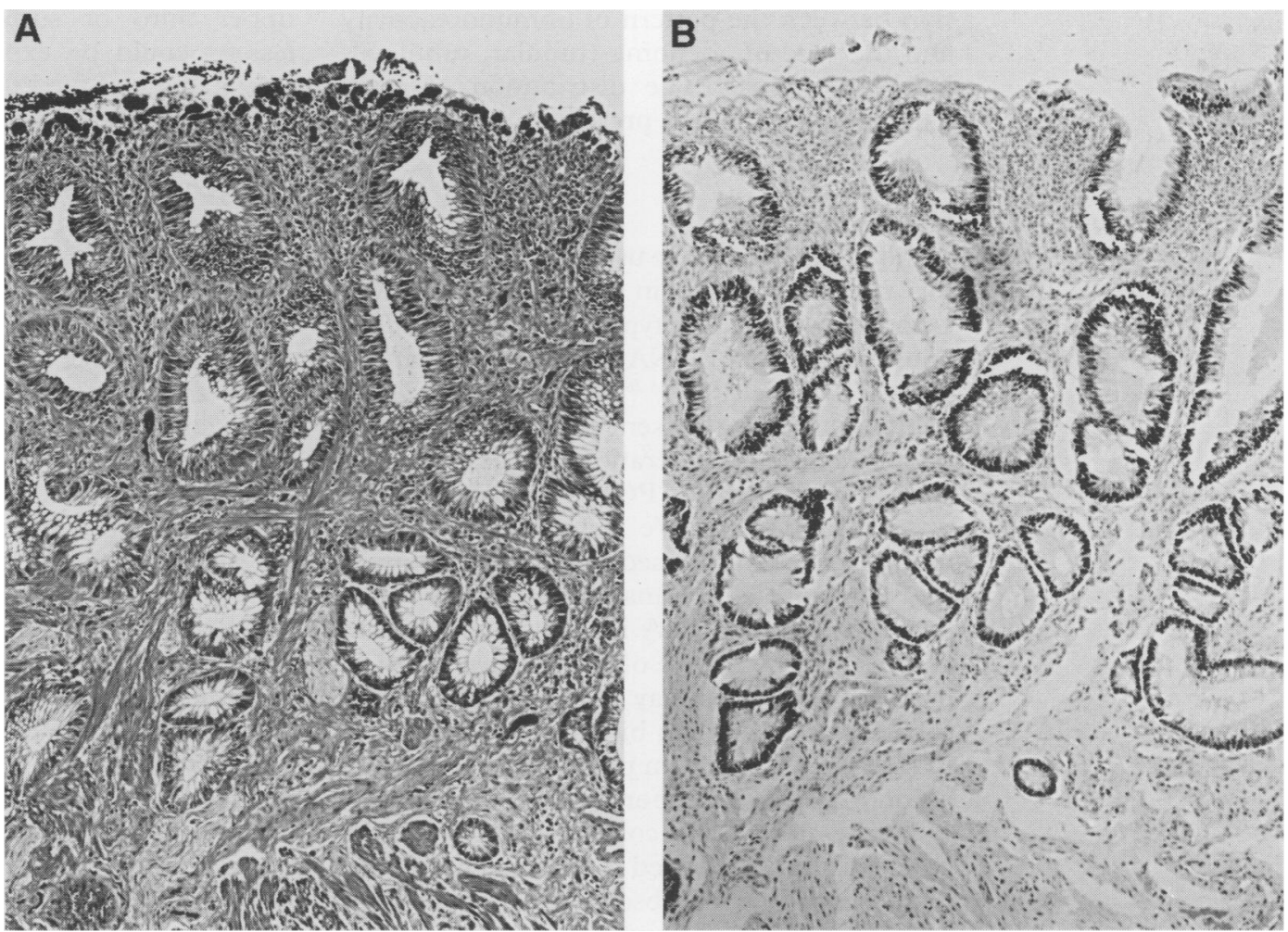

Figure 4 Inflammatory cloacogenic polyp. A: Haematoxylin and eosin stained section exhibits an eroded surface together with inflammatory cells in the lamina propria. The glands are irregular and the epithelium shows marked reactive changes. Many of the glands are surrounded by slips of smooth muscle. B: PCNA immunostaining of this lesion demonstrates widespread immunoreactivity.

two cases showed patchy staining with no obvious overall pattern. The labelling index and intensity of staining appeared to be greatest in areas of inflammatory/regenerative atypia, but there was no obvious correlation with the presence or absence of surface erosion. When all seven lesions were considered as a group, the mean labelling index of the lower third was $65 \%$ (range 18 to $85 \%$ ) and the mean labelling index of the upper third was $35 \%$ (range 0 to $82 \%$ ).

Comparison of the upper third labelling indices showed that the indices for adenomas were significantly higher than those for hyperplastic polyps or normal mucosa $(p<0.001$ in each case), whereas the indices for the upper thirds of hyperplastic polyps and normal mucosa did not differ significantly $(p>0.05)$. 
Table 2 Number of adenomas showing each of the three types of immunoreactivity based on intensity of staining and labelling indices (greatest staining in lower third, greatest staining in upper third, and mixed pattern)

\begin{tabular}{|c|c|c|c|c|}
\hline \multirow{2}{*}{$\begin{array}{l}\text { Type of } \\
\text { adenoma }\end{array}$} & \multicolumn{4}{|c|}{$\begin{array}{l}\text { Pattern of immunoreactivity } \\
n(\%)\end{array}$} \\
\hline & Lower $>$ upper & Upper $>$ lower & Mixed & Total \\
\hline $\begin{array}{l}\text { Tubular } \\
\text { Tubulovillous } \\
\text { Villous } \\
\text { Total }\end{array}$ & $\begin{array}{r}11(69) \\
5(50) \\
1(20) \\
17(55)\end{array}$ & $\begin{array}{l}4(25) \\
1(10) \\
1(20) \\
6(19)\end{array}$ & $\begin{array}{l}1(6) \\
4(40) \\
3(60) \\
8(26)\end{array}$ & $\begin{array}{r}16(100) \\
10(100) \\
5(100) \\
31(100)\end{array}$ \\
\hline
\end{tabular}

A contingency table randomisation test did not detect a significant correlation between the type of adenoma and pattern of immunoreactivity $(p>0.05)$.

The differences between the lower third samples were not significant in any of the data sets $(\mathrm{p}>0.05)$.

In 16 of $32(50 \%)$ hyperplastic polyps there was a positive signal in cells on the luminal surface. This was a higher proportion than in normal mucosa, in which eight of 23 (35\%) had positive cells on the surface. However, the $\chi^{2}$ test did not show a significant difference between these proportions ( $p>0.05$ ).

We obtained a subjective impression that the intensity of the staining reaction correlated positively with the degree of dysplasia, but there was no statistically significant relation between the pattern of immunoreactivity and the type of adenoma (tubular, tubulovillous, or villous). The distribution of cases used in this analysis is presented in table 2 .

\section{Discussion}

Although the antibody used, PC10, is suitable for use with formalin fixed, paraffin wax embedded tissue, the type and duration of fixation may effect PCNA immunoreactivity in clinical material. ${ }^{810182526}$ Moreover, low levels of PCNA may be present throughout the cell cycle. ${ }^{10}$ These considerations suggest that the results of staining for PCNA should be interpreted cautiously. We believe that loss of immunoreactivity caused by fixation factors is the most likely explanation for those cases that showed no PCNA immunoexpression at all. The patchy nature of the positive signal in many of the slides may also be attributed to such factors, although biological variability in PCNA expression from place to place within a lesion may also be important in some cases.

In the normal mucosa maximum PCNA expression was localised to the lower portions of the crypts. This observation is consistent with previous studies which showed that the proliferative zone in normal colonic epithelium is located in the lower part of the crypts; the methods used included tritiated thymidine incorporation, ${ }^{27-30}$ tritiated thymidine, uridine, and leucine in combination, ${ }^{31}$ bromodeoxyuridine uptake, ${ }^{1} \mathrm{Ki} 67$ immunoreactivity, ${ }^{32}{ }^{33}$ and PCNA immunoreactivity. ${ }^{1734}$ These studies generally found no evidence of proliferation in the upper third of the crypt or in the surface epithelium of normal intestine. However, extension of proliferative activity towards the surface has been found in macroscopically normal mucosa away from lesions in patients with large bowel adenomas, familial polyposis syndromes and carcinomas, ${ }^{2835-39}$ and in animal models of colonic oncogenesis. ${ }^{128}$ This effect has been demonstrated by PCNA in one previous study ${ }^{40}$ but not in another. ${ }^{41}$ In our material, consisting of normal crypts near the lesions but over $2 \mathrm{~mm}$ away from the closest abnormal mucosa, we regularly observed PCNA immunoexpression in the upper third of the crypts. In a proportion of our specimens, namely two of eight hyperplastic polyp cases and six of 14 adenoma cases, positive cells were present on the luminal surface.

All hyperplastic polyps in our study were positive for PCNA immunoexpression in the upper third and half showed immunoreactivity on the surface. When our data for normal mucosa and hyperplastic polyps were compared, neither the labelling indices nor the numbers of positive cells on the surface were significantly different. These findings are in keeping with those of Pignatelli et al, ${ }^{34}$ who demonstrated occasional PCNA positive cells in the upper third of hyperplastic polyps, although they contrast with a previous study using in vitro bromodeoxyuridine incorporation which found evidence of proliferation confined to the lower two thirds of the crypts. ${ }^{1}$ The finding of PCNA positive cells in the upper third or surface, or both, of these lesions could be explained by the relatively long half life of the PCNA protein. ${ }^{4}$ According to this hypothesis, an increased rate of migration from the proliferative zone towards the surface would result in immunoreactivity persisting to a higher level in the crypt. In the case of hyperplastic polyps, however, this hypothesis conflicts with evidence from electron microscopy studies and from tritiated thymidine uptake in organ cell culture, which show that maturation occurs lower in the crypt compared with normal colonic mucosa and that the rate of cell migration is slower than normal. ${ }^{342}$ According to such evidence, hyperplastic polyps represent hypermaturity of the epithelium. Assuming the cells in hyperplastic polyps migrate towards the surface more slowly than normal, then our findings could be explained by PCNA immunoreactivity persisting for longer in hyperplastic polyp cells than in normal crypt cells. Possibilities include a corresponding increase in the duration of $S$ phase or an increase in the half life of PCNA. It is of note that PCNA expression is not always associated with cell proliferation in experimental models, suggesting that PCNA is a necessary but not a sufficient requirement for DNA synthesis. ${ }^{10}$ Growth factors may regulate the stability of PCNA messenger RNA (mRNA) and protein expression, raising the possibility that changes in growth factor concentration or binding, or both, may be involved in changes in PCNA metabolism in hyperplastic polyps. ${ }^{910}$

Patterns of immunoreactivity could be divided into two main types in the adenomas. The first type showed the greatest PCNA expression in the lower third. The second type, characterised by the highest labelling indices in the upper third, may correlate with the "phase II" lesion of Lipkin, ${ }^{28}$ in which a 
net accumulation of proliferating cells at the luminal surface occurs. This concept is supported by studies of the adenoma-carcinoma sequence which show a shift in the site of the proliferating cell population towards the surface. ${ }^{1283233353643}$ In some adenomas evidence of proliferation may be confined entirely to the luminal third of the crypt, ${ }^{12284344}$ although this feature was not observed in this study. A previous study of PCNA immunoreactivity in large intestinal tubular adenomas reported that, although PCNA immunoreactive cells were found throughout the lesions, most immunoreactivity was seen in the crypt bases. ${ }^{34}$ This study also demonstrated a correlation between overexpression of p53 immunoreactivity and the PCNA labelling index. Our subjective impression that the more dysplastic areas of the lesions were associated with increased PCNA positivity is in keeping with the results of other studies in which proliferative activity has been correlated with dysplasia. ${ }^{1} 19282941$

No consistent overall pattern of immunoreactivity was observed in the inflammatory cloacogenic polyps apart from a tendency to increased immunoreactivity in areas of reactive or regenerative atypia, although the number of lesions was too small for any firm conclusions to be drawn. Nevertheless, one may speculate from our findings that PCNA labelling indices alone are unlikely to be of value in the differential diagnosis of inflammatory cloacogenic polyps. It seems likely that some of the PCNA expression occurring in these lesions is a result of its role in the repair of damaged DNA, ${ }^{10}$ as inflammatory cloacogenic polyps such as those used in this study are frequently found at the site of active inflammation and epithelial regenerative change.

In conclusion, PCNA immunoexpression was used to assess cell proliferation in routinely processed colorectal tissue; qualitative and quantitative differences were observed when adenomas were compared with hyperplastic polyps and adjacent normal mucosa. However, the great variability of PCNA expression suggests that it may be difficult to apply it to problems of differential diagnosis in the type of clinical material used in this study. PCNA expression persists into the upper portions of hyperplastic polyps, raising the possibility that the metabolism of PCNA protein may be altered in the hypermature epithelium of these lesions.

We thank the staff of the Immunohistochemistry Laboratory at the AFIP for their expert work. The opinions or assertions contained herein are the private views of the authors and are contained herein are the private views of the authors and are Department of the United States Army, or the United States Department of Defense.

1 Risio M, Coverlizza S, Ferrari A, Candelaresi GL, Rossini FP. Immunohistochemical study of epithelial cell proliferation in hyperplastic polyps, adenomas, and adeno-
carcinomas of the large bowel. Gastroenterology 1988;94: carcinomas

2 Deschner EE, Lipkin M, Solomon C. Study of human rectal epithelial cells in vitro. II. $\mathrm{H}^{3}$-thymidine incorporation into polyps and adjacent mucosa. $\mathcal{F}$ Natl Cancer Inst 1966;36:849-57.
3 Hayashi T, Yatani R, Apostol J, Stemmermann GN. Pathogenesis of hyperplastic polyps of the colon: a hypothesis based on ultrastructure and in vitro cell kinetics. Gastroenterology 1974;66:347-56.

4 Lobert PF, Appelman HD. Inflammatory cloacogenic polyp. A unique inflammatory lesion of the anal transitional zone. Am f Surg Pathol 1981;5:761-6.

5 Chetty R, Bhathal PS, Slavin JL. Prolapse-induced inflammatory polyps of the colorectum and anal transitional zone. Histopathology 1993;23:63-7.

6 Saul SH. Inflammatory cloacogenic polyp: relationship to solitary rectal ulcer syndrome/mucosal prolapse and other bowel disorders. Hum Pathol 1987;18:1120-5.

7 Jass JR, Sobin LH. Histological typing of intestinal tumours. 2nd edn. Berlin: Springer-Verlag, 1989:29-44.

8 Dietrich DR. Toxicological and pathological applications of proliferating cell nuclear antigen (PCNA), a novel endogenous marker for cell proliferation. Crit Rev Toxicol 1993;23:77-109.

9 Hall A, Levison DA, Woods AL, Yu CC-W, Kellock DB, Watkins JA, et al. Proliferating cell nuclear antigen (PCNA) immunolocalization in paraffin sections: an index of cell expression with evidence of deregulated expression in some neoplasms. I Pathol 1990;162: 285-94.

10 McCormick D, Hall PA. The complexities of proliferating cell nuclear antigen. Histopathology 1992;21:591-4.

11 Fairman MP. DNA polymerase delta/PCNA: actions and interactions. F Cell Sci 1990;95:1-4.

12 Wilcox DK, Higgins J, Bertram TA. Colonic epithelial cell proliferation in a rat model of nongenotoxin-induced colonic neoplasia. Lab Invest 1992;67:405-11.

13 Yu C C-W, Fletcher CDM, Newman PL, Goodlad JR, Burton JC, Levison DA. A comparison of proliferating Burton JC, Levison DA. A comparison of proliferating
cell nuclear antigen (PCNA) immunostaining, nucleolar organizer region (AgNOR) staining and histological grading in gastrointestinal stromal tumours. F Pathol 1992;166:147-52.

14 Lee KS, Yang WI. Comparison of brain tumor growth kinetics by proliferating cell nuclear antigen (PCNA) and bromodeoxyuridine (BrdU) labelling. Yonsei Med $\mathcal{F}$ 1992;33:265-71.

15 Tsuji T, Sasaki K, Kimura Y. Measurement of proliferating cell nuclear antigen (PCNA) and its clinical application in oral cancers. Int $f$ Oral Maxillofac Surg 1992;21:369-72.

16 Woods AL, Hall PA, Shepherd NA, Hanby AM, Waseem NH, Lane DP, et al. The assessment of proliferating cell nuclear antigen (PCNA) immunostaining in cell nuclear antigen (PCNA) immunostaining in to histological grade, $S+G 2+M$ phase fraction (flow to histological grade, $\mathrm{S}+\mathrm{G} 2+\mathrm{M}$ phase fraction (flow
cytometric analysis) and prognosis. Histopathology 1991; cytometric

17 Sarraf CE, McCormick CSF, Brown GR, Price YE, Hall PA, Lane DP, et al. Proliferating cell nuclear antigen immunolocalization in gastro-intestinal epithelia. Digestion 1991;50:85-91.

18 Diebold J, Lai MD, Lohrs U. Analysis of proliferative activity in colorectal mucosa by immunohistochemical detection of proliferating cell nuclear antigen (PCNA). Virchows Archiv B Cell Pathol 1992;62:283-9.

19 Risio M, Rossini FP. Cell proliferation in colorectal adenomas containing invasive carcinoma. Anticancer Res 1993; 13:43-8.

20 Waseem NH, Lane DP. Monoclonal antibody analysis of the proliferating cell nuclear antigen (PCNA). Structural conservation and the detection of a nucleolar form. $\mathcal{F} \mathrm{Cell}$ Sci 1990;96:121-9.

21 d'Agostino RB. Small sample probability points for the D test of normality. Biometrika 1972;59:219-21.

22 Edginton ES. Randomization tests. New York: Marcel Dekker, 1987:281-8.

23 Winer BJ. Statistical principles in experimental design. New York: McGraw Hill, 1971:283-9.

24 Brambilla $M$, Inglese E, Cannizzaro G, Dondi M, Sara $R$, Arrigo $\mathrm{F}$, et al. A muticenter trial on interobserver and intraobserver reproducibility of segmental scoring of intraobserver reproducibility of segmental scoring of thallium-201 planar myocardial imaging
reinjection. $f$ Nucl Med 1994;35:601-8.

25 McCormick D , Yu C, Hobbs C, Hall PA. The relevance of antibody concentration to the immunohistological quantification of cell proliferation-associated antigens. Histopathology 1993;22:543-7.

26 Galand P, Degraef C. Cyclin/PCNA immunostaining as an alternative to tritiated thymidine pulse labelling for marking $S$ phase cells in paraffin sections from animal and human tissues. Cell Tissue Kinet 1989;22:383-92.

27 Lipkin M, Bell B, Sherlock P. Cell proliferation kinetics in the gastrointestinal tract of man. I. Cell renewal in colon and rectum. $\mathcal{f}$ Clin Invest 1963;42:767-76.

28 Lipkin $M$. Phase 1 and phase 2 proliferative lesions of colonic epithelial cells in diseases leading to colonic cancer. Cancer 1974;34:878-88.

29 Kanemitsu T, Koike A, Yamamoto S. Study of the cell proliferation kinetics in ulcerative colitis, adenomatous proliferation kinetics in ulcerative colitis,

30 Cole JW, McKalen A. Studies on the morphogenesis of adenomatous polyps in the human colon. Cancer 1963; 16:998-1002

31 Deschner EE, Lipkin $M$. Study of human rectal epithelial cells in vitro. III. RNA, protein and DNA synthesis in polyps and adjacent mucosa. $\mathcal{F}$ Natl Cancer Inst 1970; 44:175-85.

32 Johnston PG, O'Brien MJ, Dervan PA, Carney DN. Immunohistochemical analysis of cell kinetic parameters 
in colonic adenocarcinomas, adenomas, and normal mucosa. Hum Pathol 1989;20:696-700.

33 Bedossa P, Poynard T, Bacci J, Naveau S, Lemaigre G Chaput JC, et al. Expression of histocompatibility antigens and characterization of the lymphocyte infiltrate in hyperplastic polyps of the large bowel. Hum Pathol 1990;21:319-24.

34 Pignatelli M, Stamp GWH, Kafiri G, Lane D, Bodmer WF. Over-expression of p53 nuclear oncoprotein in colorectal adenomas. Int $\mathcal{f}$ Cancer 1992;50:683-8.

35 Deschner EE, Lipkin M. Proliferative patterns in colonic mucosa in familial polyposis. Cancer 1975;35:413-18.

36 Bleiberg H, Buyse M, Galand P. Cell kinetic indicators of premalignant stages of colorectal cancer. Cancer 1985; 56:124-9.

37 Terpstra OT, van Blankenstein M, Dees J, Eilers GAM Abnormal pattern of cell proliferation in the entire colonic mucosa in patients with colon adenoma or colonic mucosa in patients with colon

38 Risio M, Lipkin M, Candelaresi GL, Bertone A, Coverlizza S, Rossini FP. Correlations between recta mucosa cell proliferation and the clinical and pathological features of nonfamilial neoplasia of the large intestine. Cancer Res 1991;51:1917-21.
39 Ponz de Leon M, Roncucci L, Donato PD, Tassi L, Smerieri O, Amorico MG, et al. Pattern of epithelial cell proliferation in colorectal mucosa of normal subjects and of patients with adenomatous polyps or cancer of the large bowel. Cancer Res 1988;48:4121-6.

40 Al-Sheneber IF, Shibata HR, Sampalis J, Jothy S. Promostic significance of proliferating J, Jothy Prognostic significance of proliferating cell nuclear antigen expression in colorectal cancer. Cancer 1993;71:

1 Risio M, Candelaresi G, Rossini FP. Bromodeoxyuridine uptake and proliferating cell nuclear antigen expression throughout the colorectal tumor sequence. Cancer Epidemiol Biomarkers Prev 1993;2:363-7.

42 Kaye GI, Fenoglio CM, Pascal RR, Lane N. Comparative electron microscopic features of normal, hyperplastic, and adenomatous human colonic epithelium. Gastroenterology 1973;64:926-45.

43 Bleiberg H, Mainguet $P$, Galand P. Cell renewal in familial polyposis: comparison between polyps and adjacent polyposis: comparison between polyps and

44 Deschner $E$, Lewis CM, Lipkin $M$. In vitro study of human rectal epithelial cells. I. Atypical zone of $\mathbf{H}^{3}$ thymidine incorporation in mucosa of multiple polyposis. F Clin Invest 1963;42:1922-8. 